\title{
Ethanol-induced Retention of Nascent Proteins in Rat Hepatocytes Is Accompanied by Altered Distribution of the Small GTP-binding Protein Rab2
}

\author{
Janet M. Larkin, Barbara Oswald, and Mark A. McNiven \\ Center for Basic Research in Digestive Diseases, Mayo Clinic and Foundation, Rochester, Minnesota 55905
}

\begin{abstract}
Chronic ethanol consumption induces hepatocellular retention of nascent proteins leading to hepatomegaly. While the molecular mechanisms behind this impairment are undefined, it has been predicted that protein retention results from a disruption of vesicle-mediated secretory processes. Small GTP-binding proteins (rab proteins) have recently been implicated in the regulation of vesicular trafficking in eukaryotic cells. Our objectives were to identify intracellular sites of ethanol-induced protein retention and to determine whether the distribution of secretory rab proteins was altered by ethanol. Transport of hepatic proteins along the secretory pathway in livers from control and ethanol-fed rats was analyzed using subcellular fractionation and immunoprecipitation in the context of in vivo pulse-chase experiments. We show that pre-Golgi and Golgi compartments, as well as secretory vesicles, are sites of ethanol-induced retention of nascent soluble and transmembrane secretory proteins. These results are supported by immunofluorescence localization of hepatic proteins on liver sections. Further, immunoblot analyses of hepatic subcellular fractions from ethanol-damaged livers indicate a dramatic reduction in the association of rab2 with a Golgi compartment as compared with controls. In contrast, rab6 and $\alpha$-mannosidase II, Golgi marker proteins, appear unchanged. These studies provide a detailed analysis of the intracellular site of ethanol-induced protein retention in the hepatocyte and lend novel insight into a potential mechanism behind this impairment. The effects of ethanol exposure on rab proteins and Golgi function are discussed. (J. Clin. Invest. 1996. 98: 2146-2157.) Key words: ethanol • vesicle-based protein trafficking $\bullet$ rab proteins $\bullet$ small guanidine triphosphate-binding proteins
\end{abstract}

\section{Introduction}

Rat hepatocytes traffic nascent proteins along the secretory pathway from the site of synthesis in the endoplasmic reticu-

Address correspondence to Mark A. McNiven, Center for Basic Research in Digestive Diseases, Mayo Clinic, 200 First Street SW, Rochester, MN 55905. Phone: 507-284-0683; FAX: 507-284-0762; E-mail: mcniven.mark@mayo.edu. Dr. Larkin's current address is Department of Biological Sciences, Barnard College, 3009 Broadway, New York, NY 10027.

Received for publication 13 September 1995 and accepted in revised form 3 September 1996.

J. Clin. Invest.

(C) The American Society for Clinical Investigation, Inc. 0021-9738/96/11/2146/12 \$2.00

Volume 98, Number 9, November 1996, 2146-2157 lum (ER $)^{1}$ to the Golgi complex for processing and transport to the sinusoidal plasma membrane for residence or secretion into blood. To accomplish this vectorial movement, hepatocytes use an elaborate yet conserved system in which membrane-bound vesicle carriers bud from one intracellular compartment for subsequent trafficking to and fusion with a specific target compartment. It has been proposed that chronic exposure to ethanol disrupts this complex series of vesiclemediated events leading to a marked accumulation of nascent protein. Indeed, seminal studies by several groups have examined the effects of acute and chronic ethanol exposure in several model systems including liver slices (1-5), whole animal models (6-8), isolated hepatocytes (9), intact livers (10), and human liver biopsies (11). All of these studies have shown that ethanol induces intracellular retention of nascent proteins and is believed responsible for the dramatic increase in diameter, or ballooning, of hepatocytes during this injury. Apparently, this secretory impairment is not due to ethanol itself but to an oxidized metabolite acetaldehyde since $(a)$ exposure of hepatocytes to drugs that prevent ethanol metabolism show normal protein secretion (6), and (b) drugs that inhibit further oxidation of acetaldehyde to acetate substantially potentiate the effects of ethanol on protein secretion $(10,12)$. The precise sites of intracellular protein retention have not been determined, although fractionation studies from ethanol-treated livers reveal that $>75 \%$ of the retained protein is in microsomalGolgi fractions $(13,14)$. All of these observations support the current dogma that hepatocytes exposed to ethanol are able to synthesize and sequester nascent proteins within the ER, but are impaired in subsequent steps of protein processing and transport. Presently, however, the mechanisms behind ethanol-induced protein retention remain undefined.

Recently, an extended family of small GTPases known as rab proteins have been identified as regulators of vesicle-mediated trafficking in various cell types (15). Multiple rab proteins participate in secretion. Rab1 and rab2 are implicated in ER to Golgi transport (16-19), rab6 in intra-Golgi transport $(20,21)$, and rab8 in post-Golgi, basolateral-directed transport (22). In addition, rab3 (a-d) are localized to secretory vesicles and are implicated in regulated exocytosis (23). The precise function of $\mathrm{rab}$ proteins in vesicle-mediated transport is unclear. However, they are thought to cycle between active GTP-bound forms and inactive GDP-bound forms to catalyze membrane budding and fusion events (24).

In this study, our aims were to identify more definitively the intracelluar site(s) of ethanol-induced protein retention and to determine whether this retention is accompanied by al-

1. Abbreviations used in this paper: $\mathrm{CVCF}$, crude vesicle carrier fraction; ER, endoplasmic reticulum; GLF, Golgi light fraction; Mt, microtubule; PGC, pre-Golgi compartment; pIgA-R, polymeric IgA receptor; SV, secretory vesicles; TC, transcytotic carriers. 
tered expression or distribution of rab proteins in hepatocytes. To this end, we have combined subcellular fractionation in the context of in vivo pulse-chase experiments and morphological techniques to identify multiple secretory compartments as sites of ethanol-induced retention of both nascent secretory and transmembrane proteins. We have used the polymeric IgA receptor (pIgA-R) as a useful marker to follow the maturation and transport of a specific protein along the secretory pathway. Immunoblot analyses of ethanol-treated hepatic subcellular fractions with antibodies to several different Golgi-associated enzymes show a significant and selective reduction in the association of rab2 (pre-Golgi marker), as opposed to rab6 and $\alpha$-mannosidase II (Golgi markers), both of which remain unchanged. Northern blot analysis of mRNA from control and ethanol-treated livers suggests that altered distribution, not expression, of rab2 is responsible for this reduction. Taken together, these studies provide novel insights into how ethanol induces hepatocellular retention of protein.

\section{Methods}

Materials. Reagents and supplies were purchased from the following sources: protein A-Sepharose beads, leupeptin, PMSF, and alkaline phosphatase-conjugated goat anti-rabbit IgG from Sigma Chemical Co. (St. Louis, MO); "Tissue-Tek" O.C.T. embedding Compound from Miles Laboratories, Inc. (Elkhart, IN); nitrocellulose filters (BA 85, 0.45-mm pores) from Fisher Scientific Co. (Pittsburgh, PA); rhodamine-conjugated goat anti-rabbit $\operatorname{IgG}(\mathrm{H}$ and $\mathrm{L})$ from Tago, Inc. (Burlingame, CA); Slowfade from Molecular Probes Inc. (Eugene, OR); SDS-PAGE reagents from Bio-Rad Laboratories (Richmond, CA); and XRP film and Tmax p3200 from Eastman Kodak Co. (Rochester, NY). Antibodies to rab2 used in this study were from Dr. B. Goud (Pasteur Institute, Paris, France) or to a synthetic peptide to rab2 (HAATNASHGGNQGGQQAGGGCC) that was conjugated to keyhole limpet hemocyanin, injected into rabbits, and purified over a peptide column.

Animal treatment. Male Sprague-Dawley rats (150-200 g) were purchased from Harlan Sprague-Dawley Inc. (Cincinnati, OH). Rats were paired according to weight and fed a Leiber-DeCarli diet (BioServ, Inc., Frenchtown, NJ) containing 36\% calories from either ethanol or isocaloric carbohydrate for 6-10 wk.

Isolation and characterization of subcellular fractions. Anesthetized rats were injected intravenously with $2 \mathrm{mCi}\left[{ }^{35} \mathrm{~S}\right]$ cysteine to biosynthetically labeled nascent hepatic proteins. At designated times after administration of label, blood was collected from the orbital venous plexus or livers were removed and homogenized in ice-cold buffer A (0.1 M Tris-HCl, pH 7.4, 0.25 M sucrose supplemented with $0.1 \mathrm{mM}$ leupeptin and $1 \mathrm{mM}$ PMSF). A $30 \%$ (wt/vol) homogenate was centrifuged $\left(7,000 \mathrm{~g}, 10 \mathrm{~min}, 4^{\circ} \mathrm{C}\right)$ to pellet nuclei, large particulates, and unbroken cells. The resulting postnuclear supernatant was centrifuged at $105,000 \mathrm{~g}$ for $90 \mathrm{~min}$ at $4^{\circ} \mathrm{C}$ to yield a cytosolic fraction and a total microsomal pellet, a fraction that contains membranebound compartments (i.e., rough and smooth ER, Golgi complex, and transport vesicles) involved in protein biosynthesis, processing, and transport. The total microsomal pellet was resuspended in buffer A and subjected to isopycnic centrifugation in discontinuous sucrose gradients to sediment rough microsomes and to generate Golgi fractions and a crude vesicle carrier fraction (CVCF) by flotation $(25,26)$. The CVCF was further subjected to ultracentrifugation in a shallow sucrose density gradient to float transcytotic carriers away from secretory vesicles (27). Calculations of total protein contained in secretory vesicles (SVs) and transcytotic carriers (TCs) from the CVCF fractions of four different control rat livers were $13 \%$ and $87 \%$, respectively. Similar proteins' contents were observed in SVs and TCs from the pair of ethanol-damaged rat livers $(15 \%$ and $82 \%$ of total fraction protein, respectively). The putative secretory vesicles are believed to represent exocytic vesicles, which contain nascent albumin as well as the precursor and intermediate forms of the pIgA-R, making them distinct from the transcytotic vesicle population as published previously (27) (see Scheme 1).

Because ethanol may have profound affects on the protein and lipid composition of membrane compartments in the hepatocyte, detailed characterization of vesicle fractions from control and ethanoldamaged livers was conducted. Both equal volume and equal protein of all membrane fractions were compared by SDS-PAGE and quantitative immunoblot analysis using antibodies to five different vesicleassociated antigens. These include antibodies to rab6, and $\alpha$-mannosidase II, as well as kinesin, and $\alpha$ - and $\gamma$-adaptin.

Immunoprecipitation of hepatic and serum proteins. As detailed in Larkin and Palade (27), total microsomes or serum samples were boiled for $2 \mathrm{~min}$ in $0.4 \%$ SDS (final concentration). Lysates were microfuged for $10 \mathrm{~min}$ at room temperature and the recovered supernatants supplemented with a Triton X-100 mixture (2\% Triton X-100 final concentration in $500 \mathrm{mM}$ Tris-HCL, $1.5 \mathrm{M} \mathrm{NaCl}$, and $20 \mathrm{mM}$ EDTA, pH 7.8) to sequester SDS (ratio of supernatant to Triton mixture is 10:1). Polymeric IgA receptors were immunoprecipitated from solubilized total microsomes and albumin from serum using antibody dilutions of 1:200 and 1:500, respectively. Antigen antibody complexes were absorbed onto protein A-Sepharose beads that were pelleted by low speed centrifugation, washed, and processed for SDSPAGE as detailed below.

Gel electrophoresis and fluorography. Equal volume and equal protein of immunoprecipitates and subcellular fractions were boiled for $2 \mathrm{~min}$ in sample buffer ( $62.5 \mathrm{mM}$ Tris- $\mathrm{HCl}, \mathrm{pH}$ 6.8, 2.7\% SDS, 100 $\mathrm{mM} \beta$-mercaptoethanol, $10 \%$ sucrose, final concentration) before being subjected to SDS-PAGE in 7.5 or $12 \%$ gels as described by Maisel (28). The loads were electrophoresed at a constant current of $25 \mathrm{~mA}$ for $\sim 2.5 \mathrm{~h}$. Gels were stained, destained, processed through fluorography, dried, and exposed to XRP film at $-80^{\circ} \mathrm{C}$ for times indicated in figure legends.

Immunoblot analysis. Proteins separated by SDS-PAGE were transferred to nitrocellulose filters that were washed in PBS, blocked with $10 \%$ dry milk (wt/vol) in PBS and processed according to Johnson et al. (29) with relevant primary antibodies overnight at $4^{\circ} \mathrm{C}$. Proteins were visualized by enzymatic detection of alkaline phosphatase-tagged secondary antibodies.

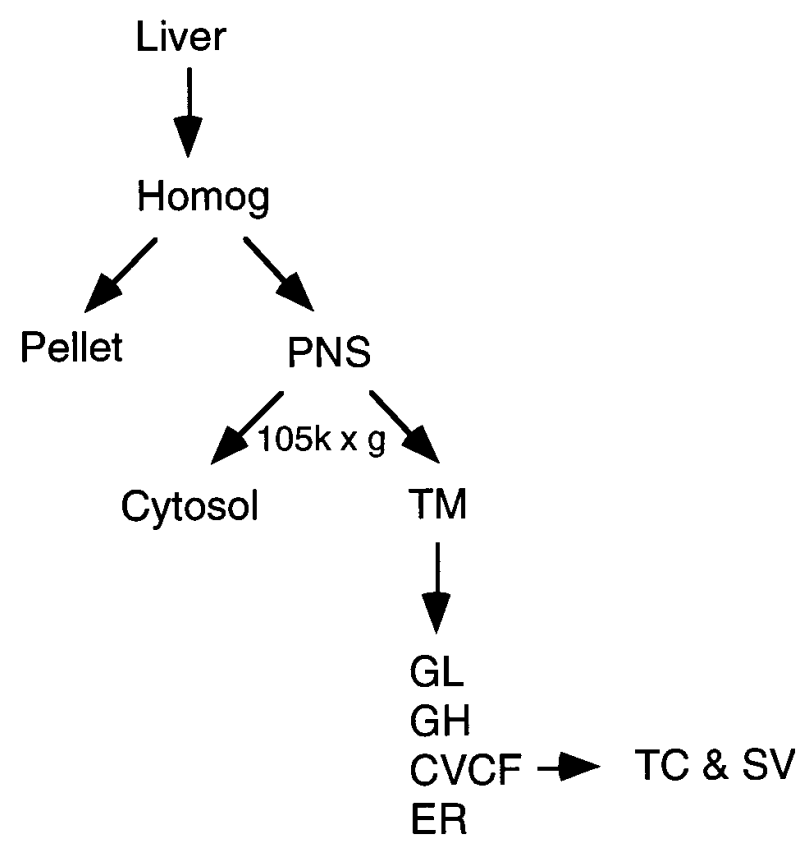

Scheme 1. 
Synthesis of a rab2 cDNA probe, RNA isolation, and Northern blot analysis. A rab2 probe was generated by amplifying a 640-bp cDNA by PCR $\left(40\right.$ cycles of $1 \mathrm{~min}$ at $94^{\circ} \mathrm{C}, 2 \mathrm{~min}$ at $45^{\circ} \mathrm{C}$, and $3 \mathrm{~min}$ at $72^{\circ} \mathrm{C}$ ) using rat liver first strand cDNA and specific primers (5'-GCCATGGCGTACGCCTATCTC-3' and 5'-AGCTAGACAGTAAAAACAGAC-3'). DNA oligonucleotides were synthesized on a synthesizer (380A; Applied Biosystems, Inc., Foster City, CA) and purified over NAP-10 columns (Pharmacia LKB Biotechnology Inc., Piscataway, NJ). Total RNA was extracted by the guanidium thiocyanate method from hepatocytes ( $98 \%$ pure) isolated from livers of pair-fed rats $(10 \mathrm{wk})$. The RNA was separated on $1 \%$ formaldehyde-agarose gel, transferred onto Hybond-N membrane (Amersham Corp., Arlington Heights, IL), and cross-linked for $12 \mathrm{~s}$ in a UV cross-linker (Stratagene Inc., La Jolla, CA). Membranes were prehybridized for $4 \mathrm{~h}$ at $68^{\circ} \mathrm{C}$ with RapidHyb (Amersham Corp.) containing denatured salmon sperm DNA at $100 \mathrm{mg} / \mathrm{ml}$. Hybridization was done overnight under the same conditions with random-primed ${ }^{32} \mathrm{P}$-labeled cDNA probes at $3 \mathrm{ng} / \mathrm{ml}$. The filters were washed in $2 \times \mathrm{SSC} / 0.1 \%$ SDS for $2 \times 30 \mathrm{~min}$, and then in $0.1 \times \mathrm{SSC} / 0.1 \% \mathrm{SDS}$ for $2 \times 30 \mathrm{~min}$ at $65^{\circ} \mathrm{C}$. The filters were exposed to $\mathrm{X}$-Omat $\mathrm{R}$ films at $-80^{\circ} \mathrm{C}$ using intensifying screens. The autoradiograms were scanned with a Umax scanner, data were analyzed using the program Image 1.47, and the data were plotted as density of the band representing the gene product of interest vs the density of the housekeeping gene glyceraldehyde-3 phosphate dehydrogenase.

Immunofluorescence analysis. Studies of liver sections were performed as follows. Unfixed pieces of rat liver were embedded in O.C.T. Compound and snap frozen in isopentane chilled in a liquid nitrogen bath. Frozen sections $(2 \mu \mathrm{m})$ were transferred to glass slides, fixed in acetone, and stored at $-80^{\circ} \mathrm{C}$ until use. Sections were warmed to room temperature and then incubated with primary antiserum in PBS, $1 \%$ BSA, and $0.02 \%$ sodium azide ( $\mathrm{pH} 7.4$ ) overnight at $4^{\circ} \mathrm{C}$, followed by incubation for $1 \mathrm{~h}$ at room temperature with rhodamine-conjugated secondary antibody (27). After washing in PBS $/ 0.1 \%$ albumin and PBS alone, sections were mounted in Slowfade. Antibody dilutions are provided in figure legends.

Studies of cultured hepatocytes were performed as follows. Hepatocytes were isolated from rat liver according to Gores et al. (30) and cultured as described by Anderson and McNiven (31). To detect rab proteins and pIgA-R, hepatocytes were quickly washed in microtubule (Mt)-stabilizing buffer (0.1 M pipes, $\mathrm{pH}$ 6.95, $1 \mathrm{mM}$ EGTA, 3 $\mathrm{mM} \mathrm{MgSO}_{4}, 5 \%$ glycerol) and permeabilized in $0.4 \%$ digitonin in Mt- stabilizing buffer for $6 \mathrm{~min}$ at $37^{\circ} \mathrm{C}$ so as to remove cytosolic proteins that might interfere with detection of membrane-associated proteins. Then the cells were fixed in $3.0 \%$ formaldehyde for $20 \mathrm{~min}$ at $37^{\circ} \mathrm{C}$. Fixed cells were washed three times quickly in DPBS at room temperature, quenched for $15 \mathrm{~min}$ in $0.01 \mathrm{M}$ glycine, and washed twice in DPBS. Cells were incubated overnight at $4{ }^{\circ} \mathrm{C}$ with primary antibody diluted in immunofluorescence blocking buffer (5\% goat serum, $5 \%$ glycerol, $0.04 \%$ sodium azide in DPBS). After three 10-min washes in DPBS, cells were incubated with rhodamine-conjugated goat antirabbit $\mathrm{IgG}$ for $60 \mathrm{~min}$ at room temperature, after which they were washed three times for 10 min each in DPBS and once in $\mathrm{H}_{2} \mathrm{O}$, blotted dry, and mounted in Slowfade. Antibody dilutions are given in figure legends.

Liver sections and cells were viewed using a $100 \times$ objective on a Zeiss Axiovert 35 epifluorescence microscope (Carl Zeiss, Inc., Oberkochen, Germany). Images were photographed on Tmax p3200 with a 35-mm camera.

Analytical procedures. Protein assays were made using a protein assay kit (Pierce Chemical Co., Rockford, IL) and bovine serum albumin as a standard. Radioactive subcellular fractions were solubilized in electrophoresis sample buffer either directly or after TCA precipitation and dissolved in Opti-fluor before counting in LS 6000SC counter (Beckman Instruments, Inc., Fullerton, CA). Counts per minute were normalized to milligrams of protein.

Statistical analysis. Data were analyzed using Student's paired $t$ test.

\section{Results}

Ethanol induces retention of nascent proteins by the liver. It is well documented that ethanol consumption causes hepatomegaly due, in part, to protein retention by hepatocytes $(1-9,11$, 12). In the present study, livers from ethanol-fed rats increased $31 \%$ in weight $(3.60 \pm 0.1503 \mathrm{~g} / 100 \mathrm{~g}$ body $\mathrm{wt})$ over control values $(2.75 \pm 0.1051 \mathrm{~g} / 100 \mathrm{~g}$ body wt; means \pm SEM of eight pairs; $P<0.0005$ by the paired Student's $t$ test).

To determine whether this retention alters the protein composition of blood, we analyzed serum samples collected from control and ethanol-fed rats. Serum proteins were separated by SDS-PAGE and visualized by Coomassie Blue stain.

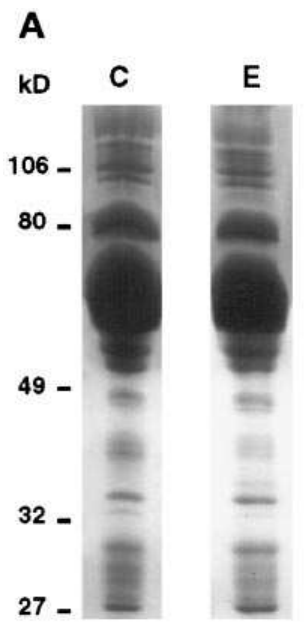

B
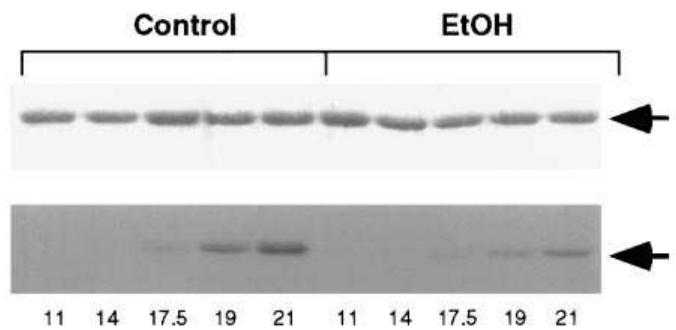

Figure 1. Ethanol alters the rate at which nascent proteins are secreted into blood. Serum proteins from control and ethanol-fed rats were analyzed by SDS-PAGE. Blood was collected from control and ethanol-fed rats before $(A)$ and at various times after $(B)$ intravenous injection of $2 \mathrm{mCi}$ of $\left.{ }^{35} \mathrm{~S}\right]$ cysteine. $(A)$ Equal volumes of serum were subjected to SDS-PAGE to separate serum proteins that were detected by Coomassie Blue stain. $(B)$ Equal volumes of serum were immunoprecipitated with antialbumin antibody (1:200). Total immunoprecipitated albumin was detected by Coomassie Blue stain ( $B$, top $)$ and the nascent component visualized by fluorography $(B$, bottom). (C) Quantitative densitometric analysis of nascent serum albumin $(B$, bottom $)$ showing a marked reduction of nascent protein secreted into the blood.

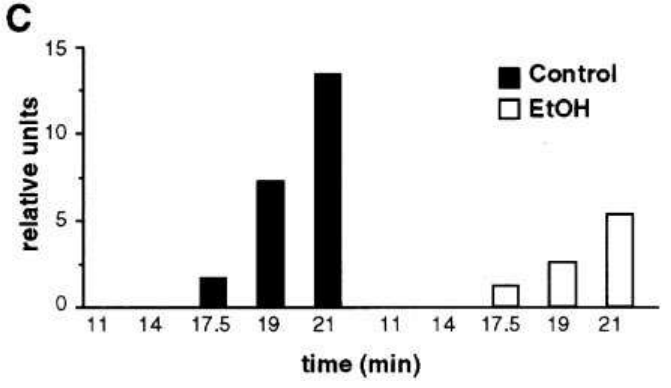


As shown in Fig. $1 A$, the total protein composition of serum collected from a pair-fed control rat $(C)$ is identical to that of an ethanol-fed rat $(E)$, indicating that chronic ethanol consumption does not selectively inhibit the synthesis and secre-

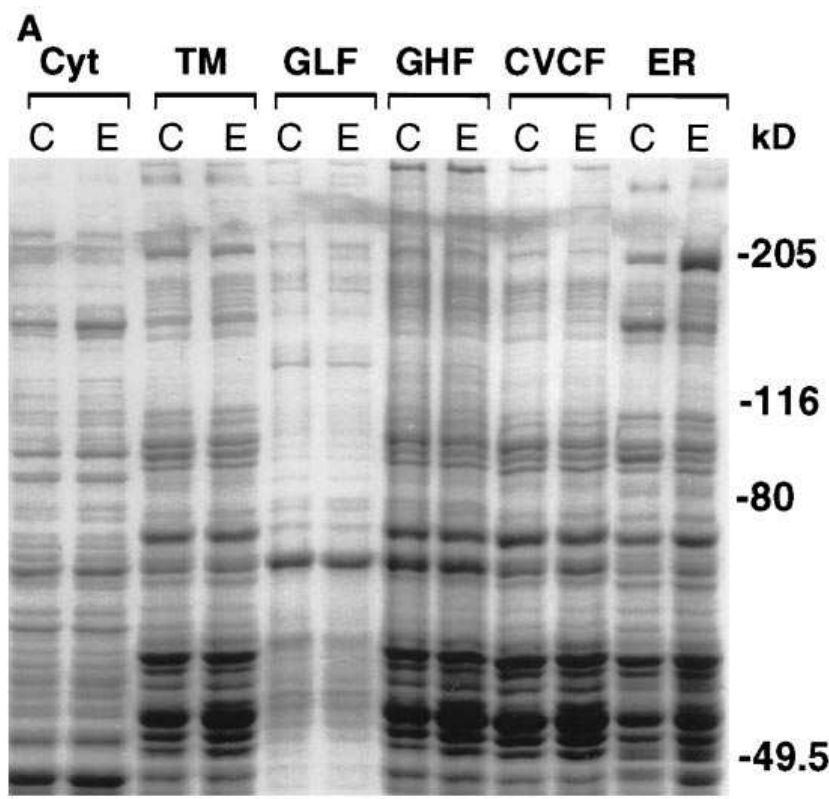

B

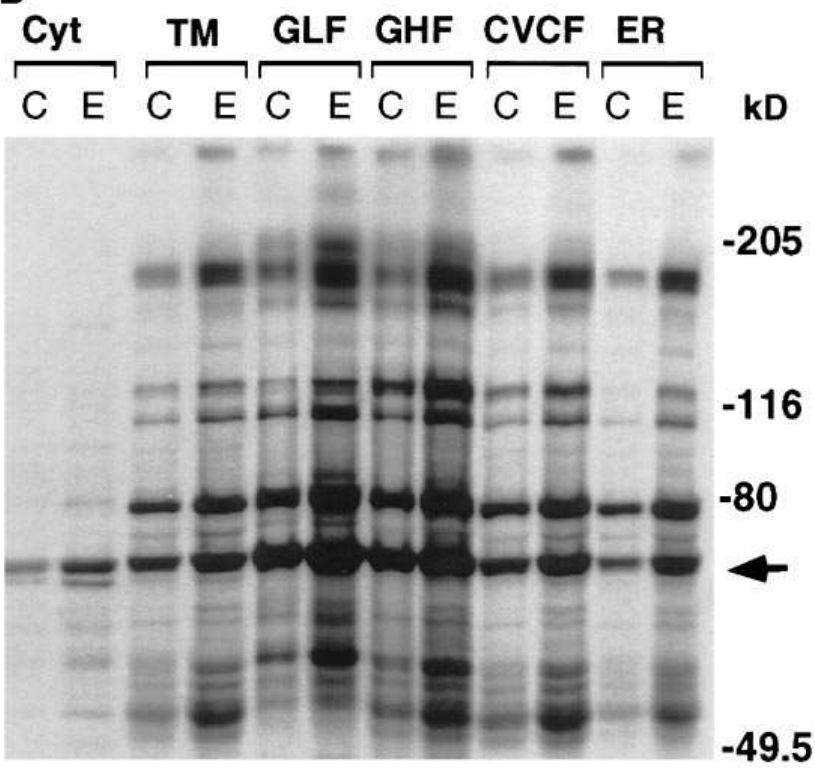

Figure 2. Nascent proteins are retained in multiple secretory compartments in response to chronic ethanol exposure. SDS-PAGE analysis of hepatic proteins in subcellular fractions identifying Golgi elements, carrier vesicles, and ER as sites of ethanol-induced protein retention. Hepatic total microsomes (TM), prepared from control and ethanol-treated rat livers $80 \mathrm{~min}$ after an intravenous injection of $2 \mathrm{mCi}$ of $\left[{ }^{35} \mathrm{~S}\right]$ cysteine, were resuspended and centrifuged in discontinuous sucrose gradients to generate Golgi fractions (GLF and $\mathrm{GHF})$, a $1.15 \mathrm{M}$ crude vesicle carrier fraction $(C V C F)$, and a fraction enriched in rough endoplasmic reticulum $(E R)$ by sedimentation. 20 $\mu \mathrm{g}$ of each fraction were subjected to SDS-PAGE before the total protein profile was detected by Coomassie Blue stain $(A)$ and $\left[{ }^{35} \mathrm{~S}\right]-$ labeled, nascent proteins were detected by fluorography $(B)$. Exposure time for $B, 7 \mathrm{~d}$ at $-80^{\circ} \mathrm{C}$. tion of specific plasma proteins into the blood. To demonstrate directly the inhibitory effect of ethanol on protein secretion, we monitored the delivery of nascent albumin into blood. After $8 \mathrm{wk}$ of treatment, control and ethanol-fed rats received intravenous injections of $\left.{ }^{35} \mathrm{~S}\right]$ cysteine, after which blood was collected at designated times postinjection. To insure that the incorporation of $\left[{ }^{35} \mathrm{~S}\right]$ cysteine into nascent protein was similar in both control and ethanol-damaged livers, we first conducted TCA precipitations on liver homogenates at 15 and $30 \mathrm{~min}$ post injection. As expected, near identical levels of $\left[{ }^{35} \mathrm{~S}\right]$ cysteine were precipitated from homogenates of control and ethanol-treated livers at these time points (at $15 \mathrm{~min}, 17,721$ and $19,121 \mathrm{cpm} / \mathrm{mg}$ from control and ethanol-treated livers, respectively; at $30 \mathrm{~min}, 22,815$ and $22,719 \mathrm{cpm} / \mathrm{mg}$ from control and ethanol-treated livers, respectively). These control experiments support the earlier observations by others indicating that protein synthesis in situ is unaffected by ethanol (32). Next, equal volumes of serum were processed through immunoprecipitation using an antibody specific for albumin. Immunoprecipitates were subjected to SDS-PAGE, and albumin was detected by Coomassie Blue stain. As shown in Fig. $1 B$ (top, arrow), equivalent amounts of albumin were immunoprecipitated from serum samples taken from control and ethanolfed rats, evidence that chronic ethanol consumption neither inhibited the synthesis nor altered the steady state level of serum albumin. The corresponding fluorograph of this gel shows the nascent albumin component immunoprecipitated from these

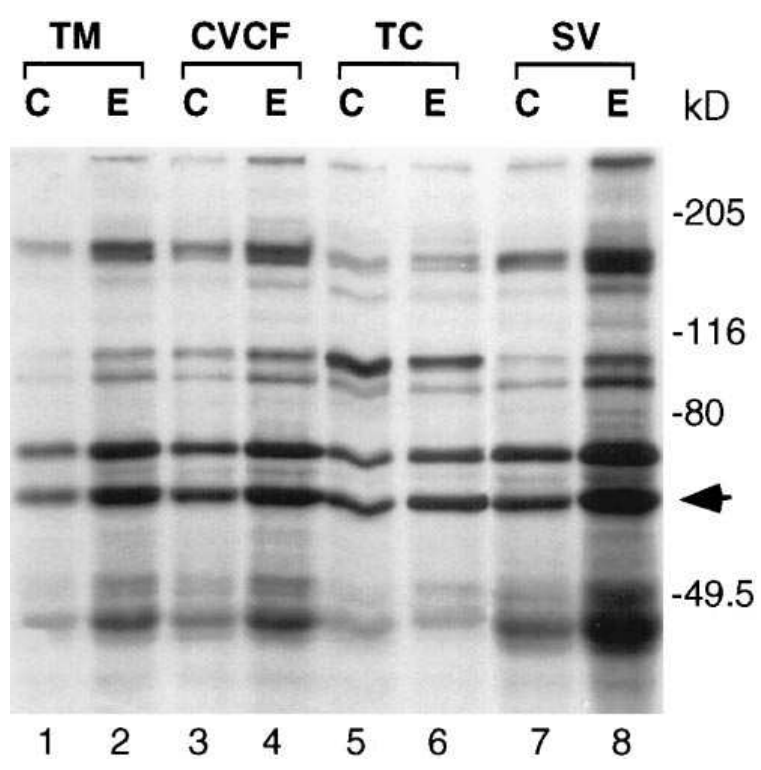

Figure 3. Nascent secretory vesicles $(S V)$ are sites of ethanol-induced protein retention. Hepatic total microsomes $(T M)$, prepared from control and ethanol-treated livers $80 \mathrm{~min}$ after an intravenous injection of $2 \mathrm{mCi}$ of $\left[{ }^{35} \mathrm{~S}\right]$ cysteine, were resuspended and centrifuged in a discontinuous sucrose gradient to generate $1.15 \mathrm{M}$ crude vesicle carrier fractions $(C V C F)$. These fractions were further subfractionated by centrifugation in shallow discontinuous sucrose gradients designed to float transcytotic carriers away from secretory vesicles (TCs and SVs contain $13 \%$ and $87 \%$ of total protein, respectively, within this fraction, see Methods for details). $10 \mu \mathrm{g}$ of appropriately pooled fractions were subjected to SDS-PAGE and nascent proteins were detected by fluorography. Exposure, $14 \mathrm{~d}$ at $-80^{\circ} \mathrm{C}$. Note the substantial increase in density of protein bands in the SV fraction isolated from ethanol-damaged liver as compared with the control. 
serum samples, thereby allowing us to determine the effect of ethanol on the kinetics of albumin secretion. As shown in Fig. $1 B$ (bottom), ${ }^{35} \mathrm{~S}$-labeled albumin was detected at $17.5 \mathrm{~min}$ postinjection in both control and ethanol-fed rats, indicating
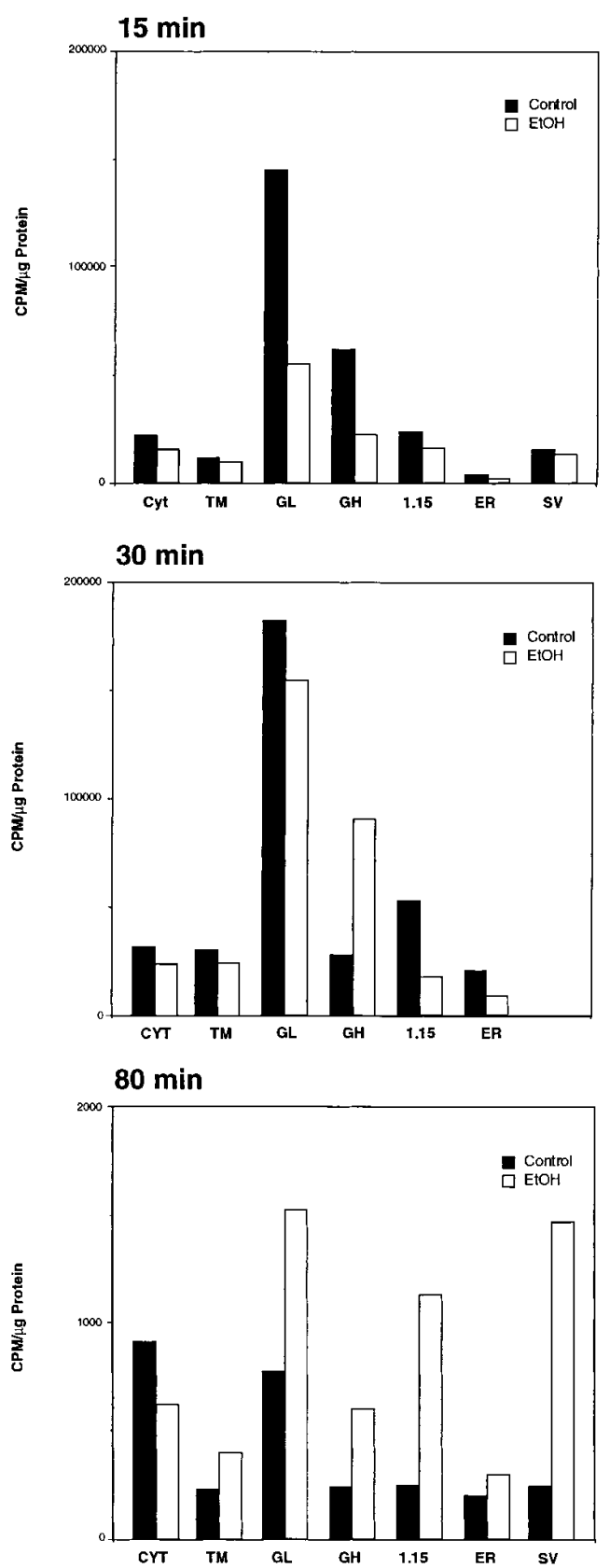

Figure 4. Scintillation analysis was used for quantitative demonstration of ethanol-induced protein retention in Golgi and secretory vesicle fractions. Subcellular organelle fractions from control or ethanoldamaged livers were isolated from rats as described in Figs. 2 and 3 at different time periods after injection with $\left[{ }^{35} \mathrm{~S}\right]$ cysteine. Radioactive subcellular fractions were solubilized in electrophoresis sample buffer either directly or after TCA-precipitation, and then dissolved in Opti-fluor before counting. Counts per minute were normalized to milligrams of protein. At early time points after injection of $\left[{ }^{35} \mathrm{~S}\right]$ cysteine (15 min), substantially more counts are found in the Golgi fractions from control vs alcohol-damaged livers. At later times postinjection, counts measured in Golgi or secretory vesicle fractions from that the secretory pathway in ethanol-treated hepatocytes was functionally intact. However, less nascent albumin was secreted into the blood of the ethanol-fed rat during the time course of the experiment, consistent with its slowed trafficking along the secretory pathway. As shown in Fig. $1 C$, quantitative densitometric analysis shows that the level of nascent albumin in plasma from the ethanol-fed rat is threefold less than that of the control at 21 min postinjection. Thus, these results are consistent with a previous report showing an ethanolinduced increase in liver mass, protein retention, and impaired discharge of albumin into blood (6).

Ethanol induces the retention of nascent protein in specific subpopulations of secretory organelles. To determine the intracellular site(s) of ethanol-induced protein retention, we used subcellular fractionation in the context of in vivo pulsechase experiments. In a representative experiment shown in Fig. 2, control and ethanol-fed rats each received $\left[{ }^{35} \mathrm{~S}\right]$ cysteine by intravenous injection and were killed 80 min postinjection. Livers were removed and subcellular fractions were prepared. Equal protein loads for each pair of fractions were analyzed for their total protein composition by SDS-PAGE and Coomassie Blue staining as shown in Fig. 2 A. Fractions analyzed include cytosol and total microsomes, a membrane preparation that was further fractionated into Golgi light (GLF) and Golgi heavy fractions, a $1.15 \mathrm{M} \mathrm{CVCF}$ and a rough microsomal pellet containing ER. Comparable cell fractions were obtained from control $(C)$ and ethanol-treated $(E)$ livers as judged by the identical protein compositions. This result is consistent with Donohue et al. (32), who showed that chronic ethanol consumption does not inhibit protein synthesis in rats. Radiolabeled proteins in each cell fraction were detected by fluorography as shown in Fig. $2 \mathrm{~B}$. Fractions isolated from ethanoldamaged livers, enriched in Golgi heavy fractions, GLF, CVCF, and ER, contained a greater concentration of nascent protein than their paired controls, suggesting that these organelles are sites of protein retention. The appearance of albumin in the cytosol could represent either albumin-containing buoyant vesicles not pelleted during centrifugation, or soluble albumin released from leaky membranes. These results are consistent with Volentine et al. (13) who used a similar fractionation protocol in conjunction with immunoprecipitation of nascent proteins. The CVCF shown in Fig. $2 B$ is of particular interest because it contains both transcytotic carriers (identified by the $120-\mathrm{kD}$ pIgA-R form) that traffic from sinusoidal to canalicular domains, as well as secretory vesicles that contain albumin and the 105- and 116-kD pIgA-R precursor forms $(27,33)$. To determine whether proteins were retained along both of these transport pathways, transcytotic carriers and secretory vesicles were subjected to SDS-PAGE, and nascent proteins were detected by fluorography (Fig. 3). Transcytotic carriers from control $(C)$ and ethanol-treated $(E)$ livers have comparable amounts of nascent proteins as judged by the equivalent intensity of protein bands in the fluorograph. In contrast, secretory vesicles from ethanol-fed rats contain a greater concentration of nascent protein compared with controls, consistent with a

ethanol-treated livers equal (30 $\mathrm{min})$, and eventually surpass ( 80 $\mathrm{min}$ ), those found in controls. These results support the fluorographic observations suggesting that alcohol induces a substantial delay of nascent proteins in different compartments of the secretory pathway. 

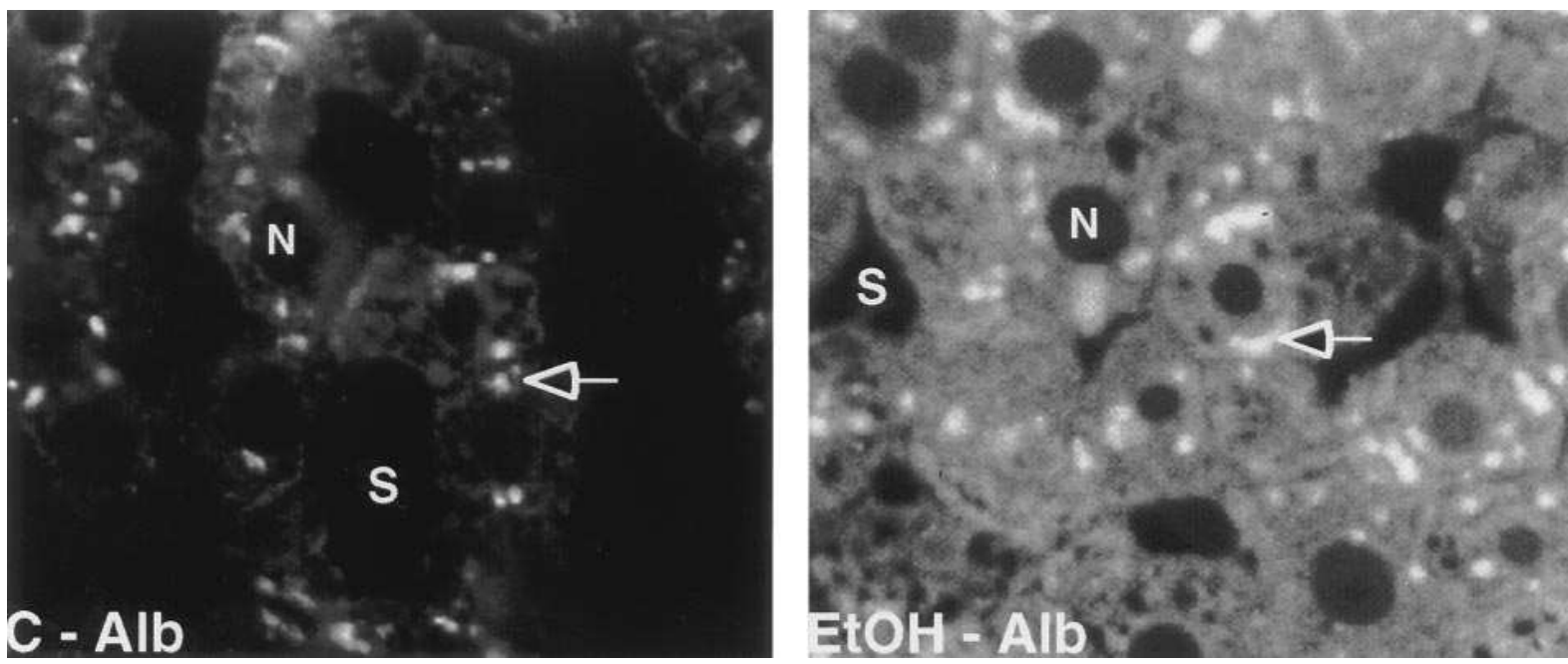

Figure 5. Morphological localization of albumin on liver sections from control and ethanol-fed rats shows marked differences in distribution. Control and ethanol-treated livers, processed for indirect immunofluorescence as described in Methods, were stained with antibodies to albumin. Light micrographs of the different fields of view were obtained by identical exposure conditions for control and ethanol-treated tissues. In control cells, albumin-positive sites are localized to punctate structures (arrows), presumably Golgi elements in the pericanalicular cytoplasm, and to diffuse cytoplasmic sites that contain markedly more antigen in ethanol-treated cells.

retention in this class of transport vesicles. These qualitative results are supported by further quantitative scintillation studies of subcellular fractions isolated from rats injected with $\left[{ }^{35}\right.$ S]cysteine (Fig. 4). These time-course experiments show that at early time points (15 min postinjection of label), the levels of nascent protein (per milligram of cell fraction protein) sequestered in the Golgi fractions from control livers exceeded that of ethanol-damaged livers by two- to threefold. By
A

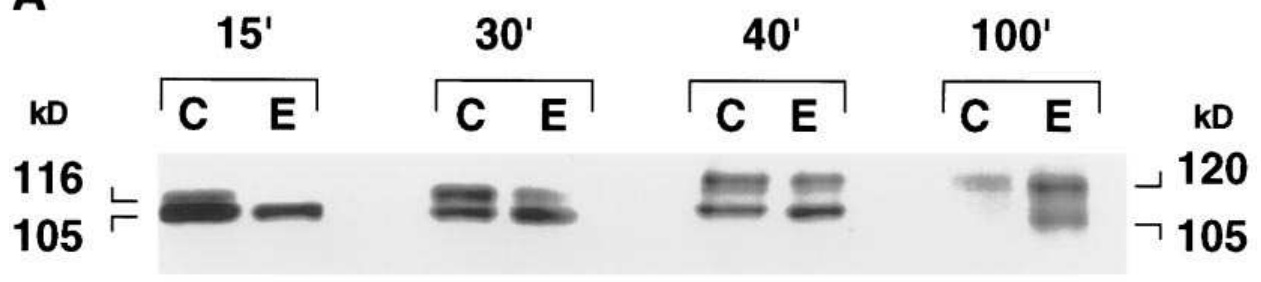

B

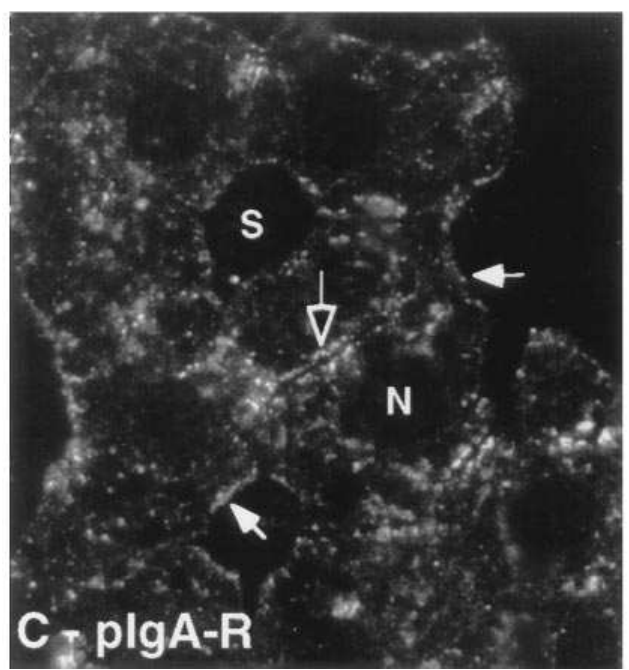

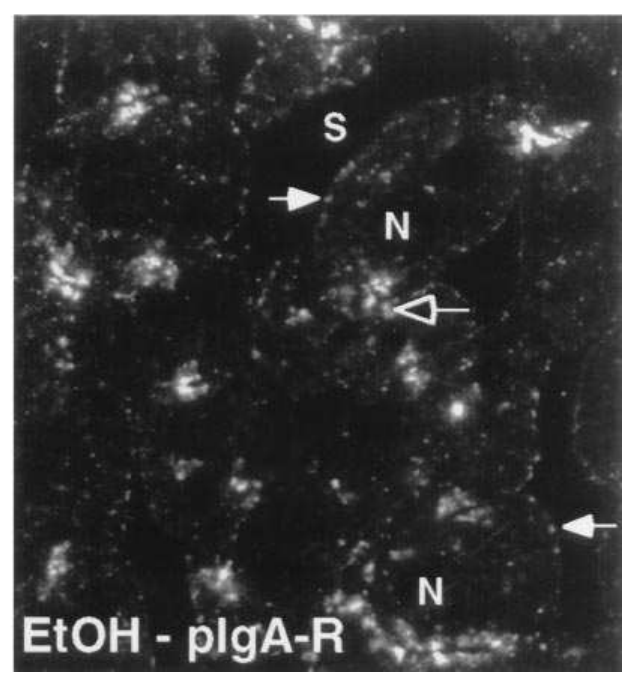

Figure 6. (A) SDS-PAGE analysis of nascent $\mathrm{pIgA}-\mathrm{R}$ from control and ethanol-fed rats demonstrating that ethanol slows the processing and transport of this transmembrane glycoprotein. Hepatic total microsomes were prepared from control and ethanol-fed rats at indicated time points after intravenous injection of $\left[{ }^{35} \mathrm{~S}\right]$ cysteine. Polymeric IgA receptors were immunoprecipitated from radiolabeled total microsomes and the immunoprecipitates were subjected to SDS-PAGE to separate precursor, intermediate, and mature receptor forms. Exposure, $14 \mathrm{~d}$ at $-80^{\circ} \mathrm{C}$. (B) Indirect immunofluorescence localization of pIgA-R on liver sections from control and ethanol-fed rats. Control and ethanoltreated livers, processed for indirect immunofluorescence as described in Methods, were reacted with polyclonal antiserum to pIgA-R (1:200) followed by rhodamine-conjugated goat anti-rabbit $\operatorname{IgG}(1: 100)$. In both control and ethanol-treated cells, pIgA-R-positive sites along the sinusoidal plasma membrane $(S$ solid arrows) appear similar. In contrast, pIgA-R appears more concentrated in perinuclear and pericanalicular foci (hollow arrows) in livers from ethanol-treated rats when compared with control staining patterns. As for the micrographs of albumin-stained tissues, all images were taken and printed at identical exposure settings. 
A
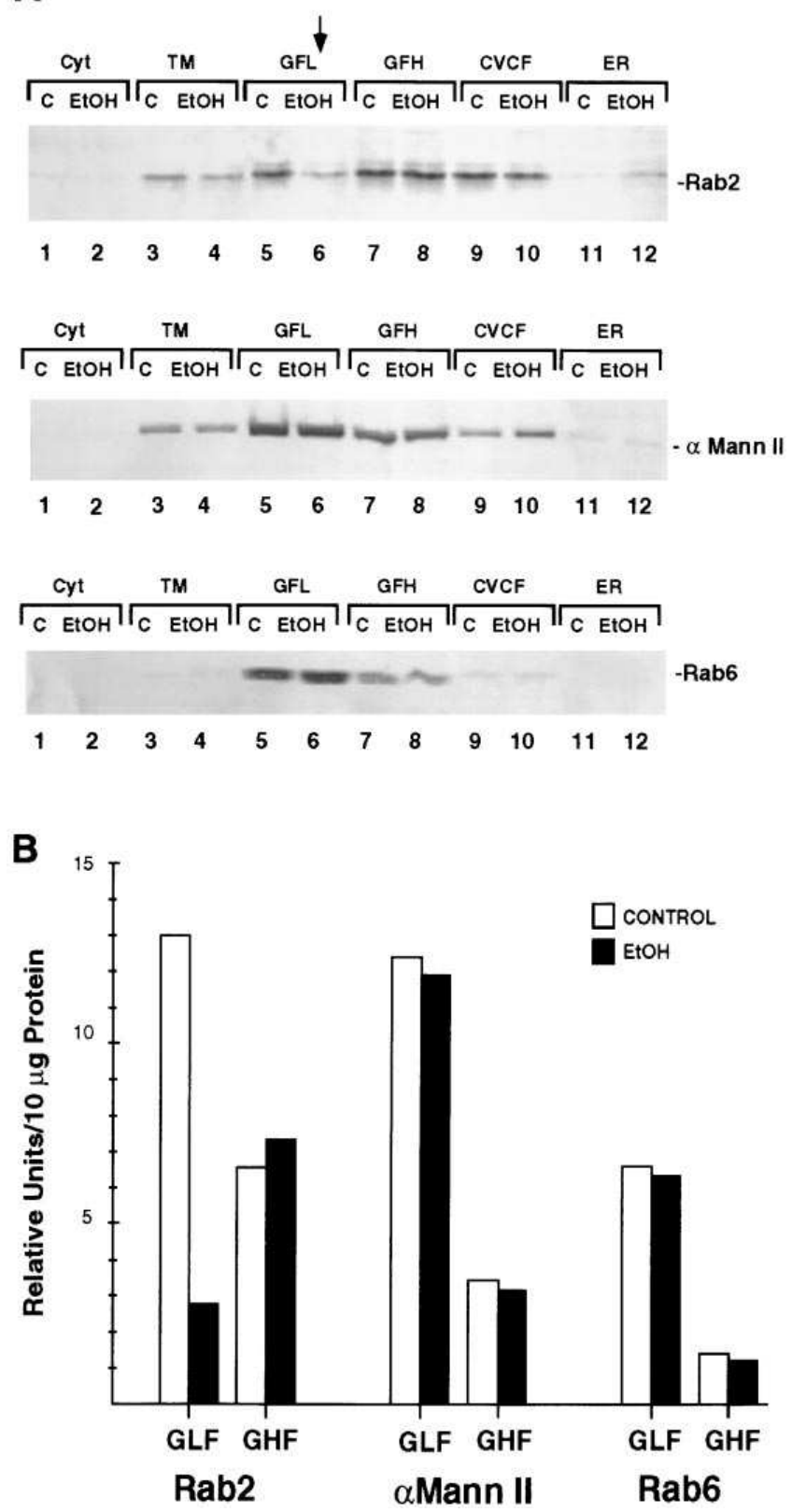

Figure 7. Altered distribution of the small GTP-binding protein, rab2, induced by chronic ethanol exposure. Immunoblot analysis was conducted for rab2 and two Golgi markers, $\alpha$-mannosidase II and rab6, in hepatic subcellular fractions from control and ethanol-treated livers. $10 \mu \mathrm{g}$ of each hepatic subcellular fraction, prepared as described in Fig. 1, were resolved by SDS-PAGE and transferred to nitrocellulose filters. The filters were reacted with polyclonal antisera specific for rab2, $\alpha$-mannosidase II, or rab6, followed by an alkaline phosphatasetagged secondary antibody. Antigens were visualized by enzymatic detection of alkaline phosphatase. As shown in the immunoblots representing one of four different experiments, the distribution of rab2, but not $\alpha$-mannosidase II or rab6, is altered by ethanol treatment.

30 min postinjection, levels of nascent protein in the ethanol Golgi fractions were equal to or exceeded that of control Golgi fractions, a trend that was accentuated further at $80 \mathrm{~min}$, particularly in the SV fraction (SV fractions for the 30-min time point

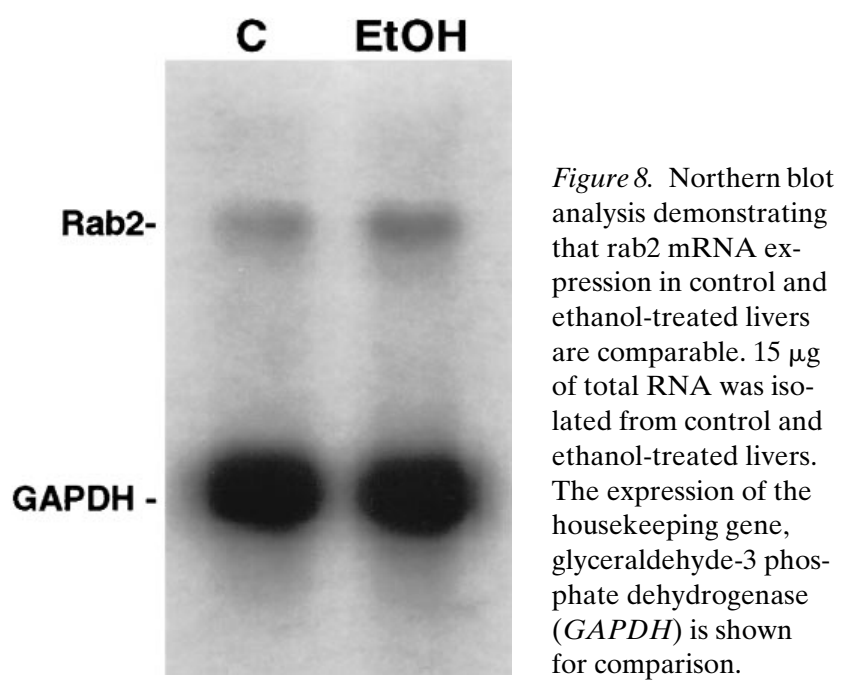

were not obtained). Thus, ethanol consumption slows transport of nascent proteins into and out of major biosynthetic organelles such as the Golgi complex and secretory vesicles.

To determine if ethanol-induced protein retention was accompanied by an altered distribution of nascent proteins in hepatocytes, we performed immunofluorescence experiments to localize albumin on control and ethanol-damaged liver sections (Fig. 5). In control hepatocytes, albumin was concentrated in the pericanalicular cytoplasm, which most likely represents Golgi elements. To a lesser extent, staining was also distributed diffusely throughout the cells, consistent with localization either to pre-Golgi compartments (i.e., ER or intermediate compartment) (34) or to secretory vesicles. In ethanol-treated liver, albumin-positive sites persisted in the pericanalicular region, consistent with localization in an intact Golgi complex. In contrast to controls, the diffuse staining pattern was greatly enhanced, indicative of protein retention by these cells.

Ethanol slows transport and processing of a transmembrane glycoprotein, the polymeric IgA receptor. To test if ethanol has a differential effect on the transport of nascent soluble and membrane proteins, we investigated the biogenesis of the rat pIgA-R in control and treated livers using immunoprecipitation in the context of an in vivo pulse-chase experiment. The pIgA-R is a transmembrane protein that is synthesized in the ER as a $105-\mathrm{kD}$ receptor precursor, terminally glycosylated in the Golgi complex to a $116-\mathrm{kD}$ intermediate, and phosphorylated to the mature $120-\mathrm{kD}$ form, presumably at the sinusoidal plasma membrane $(27,33)$. Thus, this receptor provides a convenient marker to follow the transport of a vesicle-associated protein through the secretory pathway. The fluorogram in Fig. 6 shows ${ }^{35} \mathrm{~S}$-labeled pIgA-R forms that were immunoprecipitated from hepatic total microsomes prepared at several time points after injection of $\left[{ }^{35} \mathrm{~S}\right]$ cysteine into control and ethanolfed rats. At 15 min postinjection, control membranes had detectable levels of both the $105-\mathrm{kD}$ precursor and $116-\mathrm{kD}$ intermediate receptor forms, consistent with receptor trafficking from ER to the Golgi complex. In contrast, only the $105 \mathrm{kD}$ precursor form was detected in ethanol-treated membranes, suggesting a delay in delivery to the Golgi complex. Ethanol slowed, but did not block, receptor processing as demonstrated dramatically in membranes isolated $100 \mathrm{~min}$ postinjection. At this time, pIgA-R was essentially cleared from the 

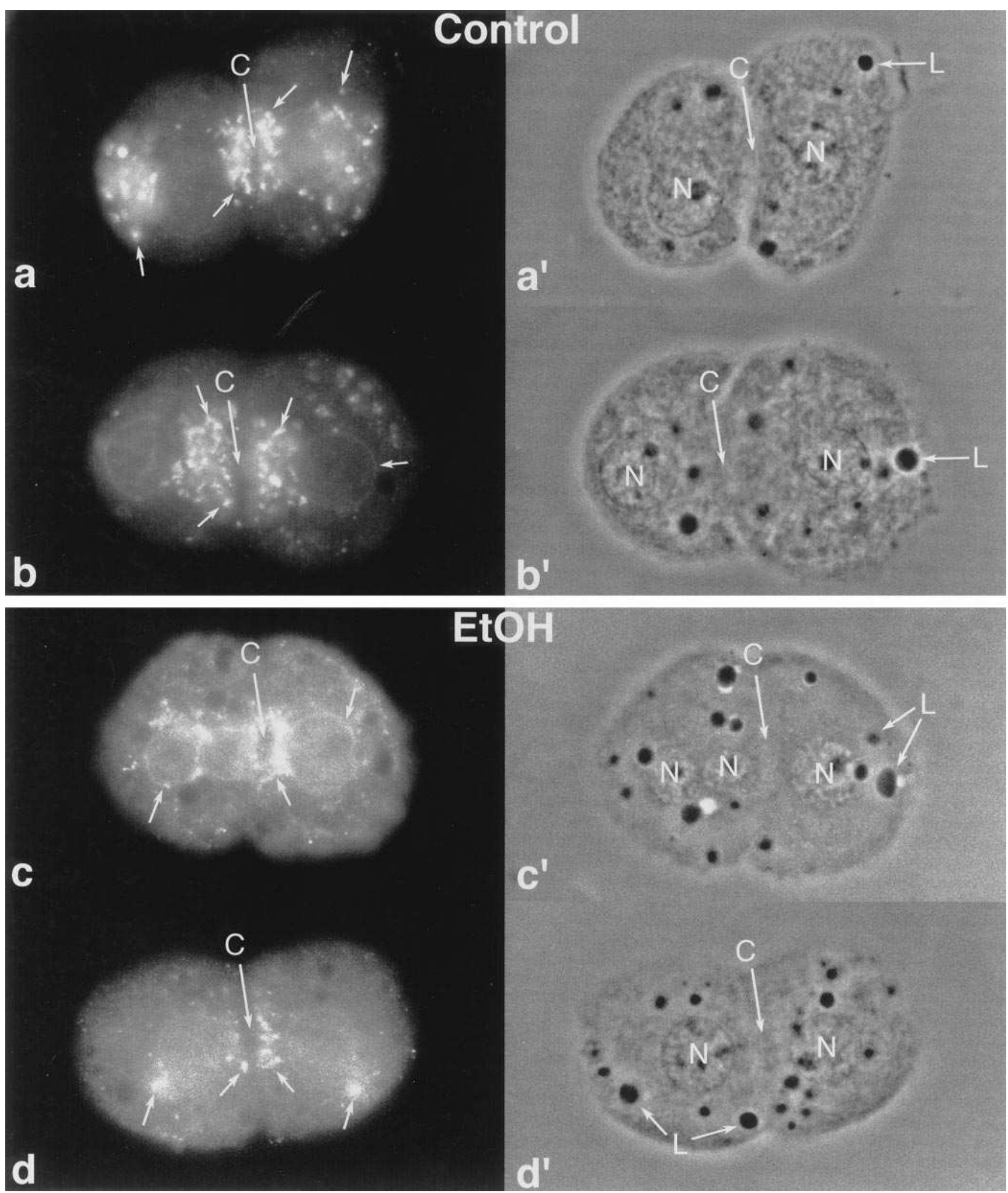

Figure 9. Indirect immunofluorescence localization of rab2 shows a decreased association with the early Golgi compartment in hepatocytes isolated from ethanol-damaged rats as compared with controls. Rat hepatocytes isolated in culture from control and ethanol-treated livers were processed for indirect immunofluorescence (a-d) and corresponding phase microscopy $\left(\mathrm{a}^{\prime}-\mathrm{d}^{\prime}\right)$ as described in Methods. Cells were stained with a polyclonal antiserum to rab2 (1:200) followed by rhodamine-conjugated goat anti-rabbit $\operatorname{IgG}(1: 100)$. In control cells $(a$ and $b)$, intensely stained rab2-positive sites (short arrows) are localized around the nuclear envelope and to numerous punctate structures in the pericanalicular cytoplasm, consistent with localization to Golgi compartments. In ethanol-treated cells $(c$ and $d$ ), rab2-positive sites are fewer in number and less clearly defined, correlating with the biochemical data shown in Fig. 7 (long arrow and $C$, bile canaliculus; $L$, lipid droplets; $N$, nucleus). 
control liver due to its transcytosis and secretion into bile. In contrast, substantial levels of pIgA-R, including precursor and intermediate forms, were detected in the ethanol-treated liver, consistent with slowed trafficking along the secretory pathway and retention in ER and Golgi compartments.

As done for albumin earlier, we performed immunofluorescence experiments to localize $\mathrm{pIg} A-\mathrm{R}$ on liver sections from control and ethanol-fed rats (Fig. $6 \mathrm{~B}$ ). In control cells, staining was localized to the sinusoidal plasma membrane and to punctate clusters in the perinuclear cytoplasm. In hepatocytes from ethanol-damaged livers, staining was restricted to the sinusoidal plasma membrane and appeared more concentrated in foci in the perinuclear and pericanalicular cytoplasm, a staining pattern similar to that of known Golgi marker proteins such as 10E6, specific for cis-Golgi cisternae, and $\alpha$-mannosidase II (data not shown). Taken together, our studies on the pIgA-R show a delay in protein processing manifested by a persistence of precursor pIgA-R forms at time points when control cells have cleared the receptor (Fig. $6 \mathrm{~A}$ ). These kinetic studies are supported by the morphologic observations (Fig. $6 \mathrm{~B}$ ) that show altered steady state distribution of pIgA-R in ethanoltreated livers, a result consistent with retention in a pre-Golgi or early Golgi compartment.

Ethanol induces the redistribution of a specific rab protein from the pre-Golgi compartment. To investigate the molecular basis of ethanol-induced protein retention, we focused our studies on specific rab proteins, small GTPases that regulate vesicle-mediated transport. Because rab2 and rab6 have been implicated in protein transport from ER through the Golgi apparatus, respectively, we hypothesized that ethanol may alter the function and distribution of these enzymes, resulting in protein retention. Thus, we examined and compared the distribution of these rab proteins in membrane fractions isolated from control and ethanol-damaged livers. To insure that vesicle fractions obtained from both control and ethanol-damaged livers were similar and equally enriched for a specific, desired organelle, all fractions were subjected to quantitative immunoblot analysis using antibodies to $\alpha$ - and $\gamma$-adaptins and kinesin (not shown), and rab 6 and $\alpha$-mannosidase II. Fig. $7 A$ shows the distribution of rab2 and two Golgi markers, $\alpha$-mannosidase II and rab6, in hepatic subcellular fractions from control and ethanol-fed rats. The GLF from the ethanol-treated liver showed a decreased level of rab2 when compared with the control. This decrease was accompanied by a slight increase in rab2 in the ER. In contrast, the GLF fractions from control and ethanol-fed rats contained comparable levels of $\alpha$-mannosidase II and rab6. Densitometric analysis of these immumoblots shown in Fig. $7 B$ revealed that rab2 in the GLF from the ethanol-treated liver was reduced fourfold when compared with control. In contrast, $\alpha$-mannosidase II and rab6 were equally enriched in GLF from both control and ethanoltreated livers, indicating that we had recovered comparable Golgi fractions from control and ethanol-fed rats. Likewise, Golgi fractions also showed an identical enrichment for the other marker proteins examined, such as the adaptins and kinesin (data not shown). The immunoblots shown in Fig. 7 represent only one series of blots from four different experiments. In each experiment, the relevant antigens were examined in triplicate immunoblot analyses of liver membrane fractions isolated from an ethanol-fed rat and its pair-fed control.

Finally, to determine if the observed decrease in rab2 was due to decreased gene expression, we performed Northern blot analysis of rab2. The Northern blot in Fig. 8 shows that the mRNA level for rab2 from an ethanol-treated liver was not decreased, but instead slightly increased, compared with the control level when normalized to a general housekeeping gene glyceraldehyde-3 phosphate dehydrogenase (GAPDH). Thus, the observed decrease in rab2 protein is probably not due to decreased expression of the rab2 gene, as judged by levels of rab2 mRNA, but is likely to represent an altered intracellular distribution of this GTPase.

To extend the biochemical observations described above, we performed immunofluorescence experiments to localize rab2 in cultured hepatocytes. Fig. $9 A$ shows that in control cells rab2 positive sites occur at the nuclear membrane as well as in compact foci in the pericanalicular cytoplasm between the nucleus and the canaliculus. In ethanol-treated cells, the nuclear membrane staining pattern appeared less well defined and in some cases lameller or layered. Further, punctate cytoplasmic staining appeared less organized and more fragmented than in control cells.

\section{Discussion}

In this study we have focused on the cellular mechanisms by which chronic ethanol consumption disrupts the secretory pathway in rat hepatocytes. First, we have validated our experimental in vivo model, the paired ethanol-feeding of rats, by confirming earlier studies showing: $(a)$ an ethanol-induced increase in liver mass; $(b)$ a reduced secretion of plasma proteins in blood (Fig. 1); and (c) an accumulation of nascent protein in crude membrane compartments (Fig. 2). Through the combination of biochemical and morphological techniques, we have extended these seminal observations to identify specific subpopulations of hepatic secretory organelles that are the sites of retention (mainly, the pre-Golgi and Golgi compartments as well as secretory vesicles) (Figs. 2-4). In addition, we have demonstrated that ethanol delays the processing and transport of a specific transmembrane protein, the pIgA-R (Fig. 6), a result consistent with an ethanol-induced delay in plasmalemma assembly (35). Finally, we have provided mechanistic insight into how ethanol may retard the transport of nascent secretory proteins (namely, a displacement of rab2 from a Golgi compartment) (Figs. 7 and 9).

Defining the intracellular sites of ethanol-induced protein retention. While it has been well established that both chronic and acute exposure to ethanol induce an intracellular retention of nascent protein (1-11), the specific secretory compartment responsible for this accumulation is unclear. Past studies have shown a significant retention of protein in crude microsomes, ER, the Golgi complex, and even cytosol $(13,14)$. The observations reported here have expanded these studies significantly through the application of additional subcellular fractionation methods (27), which obtain more defined populations of hepatocellular organelles including secretory vesicles, a heavy Golgi fraction enriched in cisternae, and a light Golgi fraction enriched in lipoprotein-containing vesicles. Although extremely useful, a method to isolate a "pre-Golgi compartment" that functions to receive and collect nascent proteins from the ER (34) is not available for liver. Both fluorographic (Figs. 2 and 3) and scintillation analyses (Fig. 4) revealed that protein retention occurs in all secretory fractions surveyed including cytosol. An increase in cytosolic protein retention was surprising, although it has been reported previously by Volen- 
tine et al. (13), who suggested this represents protein leakage from membranes or exceptionally small vesicles that did not pellet during centrifugation. The fractions that retained the most protein when compared with controls include the two Golgi fractions and, most dramatically, the secretory vesicles. This suggests that ethanol interferes with multiple steps along the secretory pathway, including transfer of protein from the pre-Golgi compartment to the Golgi stacks and the transport or release of secretory vesicles. Because the lipid and protein content of vesicle fractions isolated from control and ethanoldamaged livers may differ significantly, standardized and reproducible loading of these preparations on SDS gels for accurate comparison was absolutely essential. To insure this, membrane fractions of either equal protein (Figs. 1-4, 6, and 7) or equal volume (not shown) were both studied and provided identical results. Furthermore, comparative purity and recovery of all organelle fractions were assessed using five different marker antibodies to different vesicle-associated antigens. All of these antibody markers showed identical levels of residentassociated proteins such as $\alpha$-mannosidase II and rab 6 (Fig. 7) or $\alpha$ - and $\gamma$-adaptin, and kinesin (data not shown). These control studies strongly suggest that our isolation procedures have not been altered by an alcohol insult and that the alterations in protein accumulation and/or association represent real biological events. These biochemical observations are supported further by novel immunofluorescence images of liver sections stained with antibodies to the plasma protein albumin (Fig. 5). In control cells, modest amounts of albumin appear to reside in the Golgi, which is situated in the pericanalicular cytoplasm. In response to chronic ethanol exposure, the Golgi structures appear to become engorged with protein while the staining of the peripheral cytoplasm is also increased substantially. This cytoplasmic staining supports a pronounced accumulation of nascent protein in secretory vesicles, a heterogeneous mixture of transport organelles trafficking between ER and the Golgi complex, and between the Golgi complex and the sinusoidal plasma membrane. We believe that this retention of nascent protein in the secretory vesicles shown in Figs. 3 and 4 is important and warrants further study. Ethanol may impair exocytosis directly through an alteration in rab protein-regulated vesicle docking and fusion processes, as suggested in the case of rab2 and pre-Golgi trafficking. Alternatively, ethanol may prevent the accurate post-Golgi translocation of vesicles to the sinusoidal plasma membrane through a disruption of the $\mathrm{Mt}$ cytoskeleton as predicted previously $(36,37)$. Indeed, we have found that chronic alcohol exposure affects both Mt assembly and vesicle movement in hepatocytes (38). In the future, immunoisolation of secretory organelles using our antibodies to pIgA-R, rab proteins, and Mt-associated motor proteins will provide more insight into ethanol-induced secretory lesions.

Further detailed information on protein retention was obtained through the study of a specific glycoprotein, $\mathrm{pIgA}-\mathrm{R}$, synthesized by the hepatocyte. Because of its posttranslational modifications, we were able to measure the effects of ethanol on the transport and maturation of this protein from ER to Golgi to plasma membrane (Fig. 6). We observed impaired transport through the pre-Golgi compartment as indicated by delayed processing of precursor and intermediate receptor forms. Because ethanol has been shown to decrease the activity of resident Golgi enzymes such as galactosyltransferase (14), the accumulation of the $116-\mathrm{kD}$ receptor form could represent aberrant processing as opposed to reduced transport.
We believe that an alteration in transport is more likely since we are not aware of any data indicating that an inhibition of glycosylation impedes protein trafficking. Furthermore, the immunofluorescence localization of pIgA-R (Fig. 6) in ethanol-damaged liver, while contrasting with that of the soluble protein albumin (Fig. 5), is markedly different than that seen in control. Thus, while ethanol clearly has an effect on transport of albumin and the pIgA-R, it is unclear whether secretory and transmembrane proteins are retained in identical compartments. This important question has been addressed recently by Saucan and Palade (39) who used immunoisolation techniques to demonstrate that secretory and transmembrane hepatic proteins are delivered to the sinusoidal plasmalemma in distinct, post-Golgi secretory vesicles. It will be important to apply this novel fractionation strategy to identify the precise retention sites of these two protein classes in ethanol-treated hepatocytes.

While our studies of the pIgA-R suggest that proteins are delayed in the pre-Golgi compartment, we needed to identify the subcellular gradient fractions that were enriched in this compartment. Immunoblot analysis of these fractions with rab2-specific antibodies showed a substantial enrichment of this GTPase in Golgi light fractions prepared from control rat liver. This result was expected for two reasons. First, rab2 has been localized to intermediate and cis-Golgi compartments, where it mediates ER to Golgi transport (17). Second, the intermediate compartment, identified by an additional marker protein, p58 (34), is also enriched in hepatic Golgi light fractions (data not shown). These data suggest that the membranes derived from the intermediate compartment cofractionate with buoyant Golgi membranes in our cell fractionation protocol, and predominate in Golgi fractions that retain substantial levels of nascent protein. This observation, when combined with the pIgA-R studies, strongly implicates the pre-Golgi compartment as a target for ethanol-induced damage. Again, future studies applying immunoisolation techniques and our purified rab2 antibodies to enriched Golgi and secretory vesicle fractions will prove insightful.

Ethanol-induced impairment of the pre-Golgi compartment $(P G C)$. The observed retention of nascent protein in the PGC, like that observed in the secretory vesicles, may result from an impairment of several mechanisms. Although the Mt cytoskeleton has been implicated in most vesicle trafficking processes, its participation in ER to Golgi transport appears to be minimal based on both classic (40) and recent (41) studies using Mt poisons. Instead, alcohol may have a more potent effect through an alteration of the enzymes that mediate vesicle budding and fusion events in this compartment, such as rab2. Unlike proteins that reside in the Golgi stacks (such as $\alpha$-mannosidase II and rab6), rab2 was redistributed from Golgi to ER fractions in ethanol-treated hepatocytes, as shown by immunoblot analysis (Fig. 7). These immunoblot data suggest that ethanol may either disrupt the PGC, reduce rab2 binding, or displace it from the appropriate membrane target. Less exciting explanations for this observation would include an alcoholinduced reduction in rab2 synthesis or an aberrant separation of the precompartment during centrifugation. We have addressed these concerns by demonstrating that the expression of the rab2 gene is unaltered by alcohol (Fig. 8) and that the isolation of the pre-Golgi is not altered since other proteins that reside in this compartment-such as p58 (data not shown) or the Golgi stacks $\alpha$-mannosidase II and rab6 (Fig. 9) - appear 
relatively unchanged. Finally, immunofluorescence studies reveal a subtle ethanol-induced change in the steady state distribution of rab2 (Fig. 8). Taken together, our biochemical and morphologic data implicate rab2-dependent steps as possible targets for ethanol-induced derangements. Our results are consistent with those of Tisdale et al. (17) and Wilson et al. (19) who reported that rab2 facilitates transport from the ER to the Golgi complex, and that mutant rab1 and rab2 caused accumulation of protein in, or a structural disruption of, the PGC. Thus, ethanol-induced impairment of rab2 in hepatocytes would be expected to cause retention of protein at steps proximal to the cis-Golgi, a result obtained in our studies (Fig. 1). Because retention of nascent protein was also observed, to a lesser extent, in other compartments of the secretory pathway in hepatocytes from ethanol-damaged livers, it is likely that multiple enzymes (i.e., other rab proteins, and motor proteins) that support secretory vesicle transport are perturbed by ethanol. Future studies are designed to identify these ethanolsensitive components.

How ethanol might alter rab2 distribution and function is undefined, although it is well documented that ethanol inhibits the activity of a variety of cellular enzymes (42), including membrane-associated and soluble glycosyltransferases (43, 44), hepatic galactosyltransferase (14), and yeast glucose-6-phosphate dehydrogenase (45). A particularly relevant future line of investigation will determine whether rab proteins, including rab2 and rab6, contain reactive lysine residues available to form stable acetaldehyde-protein adducts (42). If these lysine residues are located within biologically active regions of rab proteins (i.e., GTP binding domains, effector domain), adduct formation might be expected to have profound functional consequences on secretion. Alternatively, ethanol may have indirect effects on rab proteins by modifying membrane microenvironments. For example, chronic ethanol consumption increases the fluidity of hepatic plasma membranes $(46,47)$, an alteration that could be generalized to intracellular membranes. Finally, ethanol may target the several accessory proteins that regulate rab protein function (24). Certainly future studies that focus on the effects of alcohol on rab protein enzymology, function, and distribution during secretion will prove interesting.

\section{Acknowledgments}

The authors thank Dr. B. Goud for providing antibodies to rab2 and rab6, Dr. M. Farquahar (University of California, San Diego, San Diego, CA) for the antibody to $\alpha$-mannosidase II, and Dr. W. Brown (Cornell University, Ithaca, NY) for the mAb-10E6.

This study was supported by National Institutes of Health grant AA-09227 to M.A. McNiven.

\section{References}

1. Sorrell, M.F., D.J. Tuma, E.C. Schafer, and A.J. Barak. 1977. Role of acetaldehyde in the ethanol-induced impairment of glycoprotein metabolism in rat liver slices. Gastroenterology. 73:137-144.

2. Tuma, D.J., R.B. Jennett, and M.F. Sorrell. 1981. Effect of ethanol on the synthesis and secretion of hepatic secretory glycoproteins and albumin. Hepatology. 1:590-598.

3. Sorrell, M.F., and D.J. Tuma. 1978. Selective impairment of glycoprotein metabolism by ethanol and acetaldehyde in rat liver slices. Gastroenterology. 75:200-205.

4. Tuma, D.J., R.K. Zetterman, and M.F. Sorrell. 1980. Inhibition of glycoprotein secretion by ethanol and acetaldehyde in rat liver slices. Biochem. Pharmacol. 29:35-38.

5. Tuma, D.J., and M.F. Sorrell. 1981. Effects of ethanol on the secretion of glycoproteins by rat liver slices. Gastroenterology. 80:273-278.
6. Baraona, E., M.A. Leo, S.A. Borowsky, and C.S. Lieber. 1977. Pathogenesis of alcohol-induced accumulation of protein in the liver. J. Clin. Invest. 60 : $546-554$.

7. Baraona, E., P. Pikkarainen, M. Salaspuro, F. Finkelman, and C.S. Lieber. 1980. Acute effects of ethanol on hepatic protein synthesis and secretion in the rat. Gastroenterology. 79:104-111.

8. Volentine, G.D., D.J. Tuma, and M.F. Sorrell. 1984. Acute effects of ethanol on hepatic glycoprotein secretion in the rat in vivo. Gastroenterology. 86: 225-229.

9. Wood, C., and R.G. Lamb. 1979. The effect of ethanol on glycerolipid biosynthesis by primary monolayer cultures of adult rat hepatocytes. Biochim. Biophys. Acta. 572:121-131.

10. Volentine, G.D., K.A. Ogden, D.K. Kortje, D.J. Tuma, and M.F. Sorrell. 1987. Role of acetaldehyde in the ethanol-induced impairment of hepatic glycoprotein secretion in the rat in vivo. Hepatology. 7:490-495.

11. Matsuda, Y., A. Takada, H. Sato, M. Yasuhara, and S. Takase. 1985. Comparison between ballooned hepatocytes occurring in human alcoholic and nonalcoholic liver diseases. Alcohol. Clin. Exp. Res. 9:366-370.

12. Marchner, H., and O. Tottmar. 1978. A comparative study on the effects of disulfiram, cyanamide and 1-aminocyclopropanol on acetaldehyde metabolism in rats. Acta Pharmacol. Toxicol. 43:219-232.

13. Volentine, G.D., D.J. Tuma, and M.F. Sorrell. 1986. Subcellular location of secretory proteins retained in the liver during the ethanol-induced inhibition of hepatic protein secretion in the rat. Gastroenterology. 90:158-165.

14. Guasch, R., J. Renau-Piqueras, and C. Guerri. 1992. Chronic ethanol consumption induces accumulation of proteins in the liver Golgi apparatus and decreases galactosyltransferase activity. Alcohol. Clin. Exp. Res. 16:942-948.

15. Zerial, M., and H. Stenmark. 1993. Rab GTPases in vesicular transport. Curr. Opin. Cell Biol. 5:613-620.

16. Plutner, H., A.D. Cox, S. Pind, R. Khosravi-Far, J.R. Bourne, R Schwaninger, C.J. Der, and W.E. Balch. 1991. Rab1b regulates vesicular transport between the endoplasmic reticulum and successive Golgi compartments. $J$. Cell Biol. 115:31-43.

17. Tisdale, E.J., J.R. Bourne, R. Khosravi-Far, C.J. Der, and W.E. Balch 1992. GTP-binding mutants of rab1 and rab2 are potent inhibitors of vesicular transport from the endoplasmic reticulum to the Golgi complex. J. Cell Biol. 119:749-761.

18. Nuoffer, C., H.W. Davidson, J. Matteson, J. Meinkoth, and W.E. Balch. 1994. A GDP-bound of rab1 inhibits protein export from the endoplasmic reticulum and transport between Golgi compartments. J. Cell Biol. 125:225-237.

19. Wilson, B.S., C. Nuoffer, J.L. Meinkoth, M. McCaffery, J.R. Feramisco, W.E. Balch, and M.G. Farquhar. 1994. A rab1 mutant affecting guanine nucleotide exchange promotes disassembly of the Golgi apparatus. J. Cell Biol. 125: 557-571.

20. Antony, C., C. Cibert, G. Geraud, A. Santa Maria, B. Maro, V. Mayau, and B. Goud. 1992. The small GTP-binding protein rab6p is distributed from medial Golgi to the trans-Golgi network as determined by a confocal microscopic approach. J. Cell Sci. 103:785-796.

21. Martinez, O., A. Schmidt, J. Salamero, B. Hoflack, M. Roa, and B. Goud. 1994. The small GTP-binding protein rab6 functions in intra-Golgi transport. J. Cell Biol. 127:1575-1588.

22. Huber, L.A., S. Pimplikar, R.G. Parton, H. Virta, M. Zerial, and K. Simons. 1993. Rab8, a small GTPase involved in vesicular traffic between the TGN and the basolateral plasma membrane. J. Cell Biol. 123:35-45.

23. Fischer von Mollard, G., B. Stahl, C. Li, T. C. Südhof, and R. Jahn. 1994 Rab proteins in regulated exocytosis. TIBS (Trends Biochem. Sci.). 19:164-168.

24. Pfeffer, S.R. 1994. Rab GTPases: master regulators of membrane trafficking. Curr. Opin. Cell Biol. 6:522-526.

25. Ehrenreich, J.H., J.J.M. Bergeron, P. Siekevitz, and G.E. Palade. 1973. Golgi fractions prepared from rat liver homogenates. J. Cell Biol. 59:45-72.

26. Howell, K.E., and G.E. Palade. 1982. Hepatic Golgi fractions resolved into membrane and content subfractions. J. Cell Biol. 92:822-832.

27. Larkin, J.M., and G.E. Palade. 1991. Transcytotic vesicular carriers for polymeric IgA receptors accumulate in rat hepatocytes after bile duct ligation. J. Cell Sci. 98:205-216.

28. Maisel, J.V. 1971. Polyacrylamide gel electrophoresis of viral proteins. In Methods in Virology. K. Maramorosh and H. Kiprowski, editors. Academic Press Inc., New York. 179-246.

29. Johnson, D.A., J.W. Gautsch, J.R. Sportsman, and J.H. Elder. 1984. Improved technique utilizing nonfat dry milk for analysis of proteins and nucleic acids transferred to nitrocellulose. Gene Anal. Tech. 1:3-8.

30. Gores, G.J., A.-L. Neiminen, B.E. Wray, B. Herman, and J.J. Lemasters. 1989. Intracellular pH during "chemical hypoxia" in cultured rat hepatocytes. Protection by intracellular acidosis against the onset of cell death. J. Clin. Invest. 83:386-396.

31. Anderson, K.L., and M.A. McNiven. 1995. Vesicle dynamics during regulated secretion in a novel pancreatic acinar cell in vitro model. Eur. J. Cell Biol. 66:25-38.

32. Donohue, T.M., Jr., M.F. Sorrell, and D.J. Tuma. 1987. Hepatic protein synthetic activity in vivo after ethanol administration. Alcohol. Clin. Exp. Res. 11:80-86.

33. Sztul, E.S., A. Kaplin, L. Saucan, and G. Palade. 1991. Protein traffic between distinct plasma membrane domains: isolation and characterization of ve- 
sicular carriers involved in transcytosis. Cell. 64:81-89.

34. Saraste, J., and E. Kuismanen. 1992. Pathways of protein sorting and membrane traffic between the rough endoplasmic reticulum and the Golgi complex. Semin. Cell Biol. 3:343-355.

35. Tuma, D.J., M.E. Mailliard, C.A. Casey, G.D. Volentine, and M.F. Sorrell. 1986. Ethanol-induced alterations of plasma membrane assembly in the liver. Biochim. Biophys. Acta. 856:571-577.

36. Matsuda, Y., E. Baraona, M. Salaspuro, and C.S. Lieber. 1979. Effects of ethanol on liver microtubules and Golgi apparatus: possible role in altered hepatic secretion of plasma proteins. Lab. Invest. 41:455-463.

37. Jennett, R.B., D.J. Tuma, and M.F. Sorrell. 1980. Effect of ethanol and its metabolites on microtubule formation. Pharmacology (Basel). 21:363-368.

38. Török, N., Y. Yoon, and M.A. McNiven. 1995. Alcohol-induced alterations in the hepatocyte microtubule cytoskeleton and associated vesicle movement. Hepatology. 22:478a.

39. Saucan, L., and G.E. Palade. 1994. Membrane and secretory proteins are transported from the Golgi complex to the sinusoidal plasmalemma of hepatocytes by distinct vesicular carriers. J. Cell Biol. 125:733-741.

40. Redman, C.M., D. Banerjee, K. Howell, and G.E. Palade. 1975. Colchicine inhibition of plasma protein release from rat hepatocytes. J. Cell Biol. 66:
$42-59$.

41. Lippincott-Schwartz, J. 1993. Membrane cycling between the ER and Golgi apparatus and its role in biosynthetic transport. Subcell. Biochem. 21:95-119.

42. Sorrell, M.F., and D.J. Tuma. 1987. The functional implications of acetaldehyde binding to cell constituents. Ann. NY Acad. Sci. 492:50-62.

43. Fernandez-Briera, A., P. Louisot, and R. Morelis. 1990. Effects of chronic ethanol administration on plasma-membrane-bound glycosyltransferase activities. Pharmacol. Biochem. Behav. 35:75-84.

44. Stibler, H., and S. Borg. 1991. Glycoprotein glycosyltransferase activities in serum in alcohol-abusing patients and healthy controls. Scand. J. Clin. Lab. Invest. 51:43-51.

45. Mauch, T.J. T.M. Donohue, R.K Zetterman, M.F Sorrell, and D.J. Tuma. 1986. Covalent binding of acetaldehyde selectively inhibits the catalytic activity of lysine-dependent enzymes. Hepatology. 6:263-269.

46. Yamada, S., and C.S. Lieber. 1984. Decrease in microviscosity and cholesterol content of rat liver plasma membranes after chronic ethanol feeding. $J$. Clin. Invest. 74:2285-2289.

47. Harris, R.A., R. Burnett, S. McQuilkin, A. McClard, and F.R. Simon. 1987. Effects of ethanol on membrane order: fluorescence studies. Ann. NY Acad. Sci. 492:125-135. 